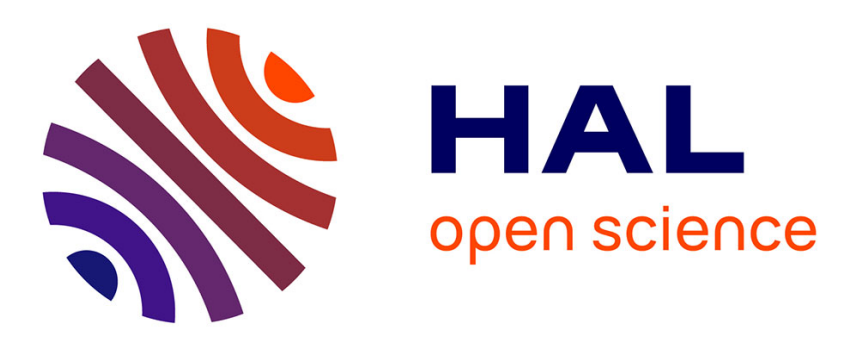

\title{
Characterizing faulted dipoles in TiAl with electron microscopy and computed image simulations
}

\author{
B. Viguier, K. Hemker, R. Schäublin, J. Martin
}

\section{To cite this version:}

B. Viguier, K. Hemker, R. Schäublin, J. Martin. Characterizing faulted dipoles in TiAl with electron microscopy and computed image simulations. Journal de Physique IV Proceedings, 1993, 03 (C7), pp.C7-441-C7-444. 10.1051/jp4:1993768 . jpa-00252188

\section{HAL Id: jpa-00252188 https://hal.science/jpa-00252188}

Submitted on 1 Jan 1993

HAL is a multi-disciplinary open access archive for the deposit and dissemination of scientific research documents, whether they are published or not. The documents may come from teaching and research institutions in France or abroad, or from public or private research centers.
L'archive ouverte pluridisciplinaire HAL, est destinée au dépôt et à la diffusion de documents scientifiques de niveau recherche, publiés ou non, émanant des établissements d'enseignement et de recherche français ou étrangers, des laboratoires publics ou privés. 


\title{
Characterizing faulted dipoles in TiAl with electron microscopy and computed image simulations
}

\author{
B. VIGUIER, K.J. HEMKER, R. SCHÄUBLIN and J.L. MARTIN \\ Institut de Génie Atomique, Ecole Polytechnique Fédérale, 1015 Lausanne, Switzerland
}

\begin{abstract}
The low temperature deformation microstructure of TiAl is dominated by the presence of stacking fault dipoles [1]. Two different faulted dipole geometries have been proposed in the literature $[2,3]$, and the existence of both types of faulted dipoles have been verified in the present study with comparisons to computer simulated images. These comparisons suggest that extrinsic stacking faults in TiAl are bounded by single Shockley partial dislocations when the deformation occurs at room temperature and by double Shockley partial dislocations when the deformation occurs at $80 \mathrm{~K}$. This change in the faulted dipole geometry is believed to be related to a change in the activity of the super dislocations that control deformation.
\end{abstract}

\section{Introduction.}

The properties of the intermetallic compound TiAl make it a serious candidate for structural applications in the aerospace and aeronautic industries [4]. These properties include : good high temperature strength retention, a high modulus of elasticity, a low density $\left(3.8 \mathrm{~g} / \mathrm{cm}^{3}\right)$, and good environmental resistance. Like many other intermetallic alloys, the mechanical behavior of TiAl is related to its ordered structure $\left(\mathrm{L} 1_{0}\right)$. This tetragonal structure is nearly cubic $(\mathrm{c} / \mathrm{a}=1.02)$ but it is also chemically anisotropic, and a relatively large number of different deformation modes are possible. Controlling deformation mechanisms have been found to depend on both the load axis and the deformation temperature, and TEM studies have shown the presence of twins [5,6], faulted dipoles [2,3], simple dislocations $\left.\left(b_{\text {simple }}=a / 2<110\right]\right)[7,8]$, super dislocations of the type $\left.\left(b_{\text {super }}=a<101\right]\right)[9]$, and super dislocations of the type $\left(b_{\text {super }}=a / 2<112\right]$ ) $[2,10]$ (note: the brackets used follow the convention introduced by Hug [2]).

The work presented here focuses on the faulted dipoles that dominate the low temperature deformation microstructure. Stacking fault dipoles were observed, in $\mathrm{Ti}_{46} \mathrm{Al}_{54}$ specimens that were deformed at room temperature (RT), and characterized as extrinsic stacking faults bounded by a single Shockley partial dislocation $\left(\mathbf{b}_{\text {partial }}=1 / 6<112\right]$ ) dipole by Hug and co-workers [2]. More recently, Zhang et al. [3] studied the dipoles associated with $\mathrm{RT}$ deformation in $\mathrm{Ti}_{48} \mathrm{Al}_{52}$, and reported that, while the majority of dipoles were of the type reported by Hug, there were "a few" extrinsic faults that were bounded by double Shockley partial dislocations $(b$ partial $=1 / 3<211]$ ). Viguier $e t$ al . [11] have shown that the bounding dislocations can have a very strong effect on the the fault contrast and that the characterization of stacking fault dipoles can best be done by comparisons with image simulations. Hug et al. [2] compared their experimental observations with image simulations, but the observations of Zhang et al. [3] have not been simulated. In the present study, we have verified the existence of both types of faulted dipoles by comparing our experimental observations with image simulations, and we have studied two different alloys and deformation temperatures in an attempt to shed light on the occurrence of the second type of faulted dipole. 


\section{Experimental procedures.}

Two TiAl alloys ( $\mathrm{Ti}_{46} \mathrm{Al}_{52} \mathrm{Mn}_{2}$ andTi ${ }_{46} \mathrm{Al}_{53} \mathrm{Nb}_{1}$ ) were provided for this study by Pat Martin of Rockwell International and Bob Hayes of Metals Technology, USA. These materials are single phase and polycrystalline with an average grain size of $200 \mu \mathrm{m}$. Compression specimens $\left(3 \times 3 \times 10 \mathrm{~mm}^{3}\right)$ of both alloys were deformed (to $\varepsilon_{\mathrm{p}}=1 \%$ ) at $\mathrm{RT}$ with a constant strain-rate of $\left(3 \times 10^{-5} \mathrm{~s}^{-1}\right)$. The Ti46 $\mathrm{Al}_{53} \mathrm{Nb}_{1}$ alloy was also deformed in a two stage process (constant strain-rate deformation to $\varepsilon_{\mathrm{p}}=1 \%$ at $80 \mathrm{~K}$ followed by a 5 hour high temperature relaxation at $873 \mathrm{~K}$ and $300 \mathrm{MPa}$ ) that is similar to the procedure that Greenberg [10] proposed as a means for locking in the low temperature dislocation structure.

Thin foils were electro-discharge machined and electropolished in a Tenupol using Struers "A3" solution at $235 \mathrm{~K}$ and 15 volts. All TEM observations were carried out using the Philips CM20 at the Institut Interdépartemental de Microscopie in the EPFL. A quantitative interpretation of the micrographs has been accomplished by comparing the observations with images calculated by the many-beam image simulation program "Cufour" [12].

\section{Results and discussion}

3.1 MECHANICAL PROPERTIES. - Figure 1 gives the flow stress for $0.2 \%$ plastic deformation normalized by the density as a function of the deformation temperature. Measured values for the two TiAl alloys used in this study and data for a polycrystalline $\mathrm{Ni}_{3} \mathrm{Al}$ alloy that was taken from [13] are given in this graph. Both intermetallic alloys show the well known anomalous, positive, dependence of the yield stress with the deformation temperature, but the particular interest in TiAl alloys, namely their good strength to weight ratio, is highlighted in this normalized plot. The retention of RT strength is much higher for TiAl than it is for $\mathrm{Ni}_{3} \mathrm{Al}$. This effect, which can be good if one requires high room temperature strength but bad if one is worried about room temperature brittleness, may be the result of a change in dislocation mechanisms that occurs in TiAl but not in $\mathrm{Ni}_{3} \mathrm{Al}$.

3.2 TEM OBSERVATIONS. - The low temperature deformation microstructure in the two alloys deformed in this study is dominated by the presence of faulted dipoles, see fig. 2. These stacking faults can be either intrinsic or extrinsic stacking faults. They are not formed by the dissociation of a unit dislocation, but are instead formed by the drawing out of either single $\left.\left(b_{p}= \pm a / 6<112\right]\right)$ or double $\left.\left(b_{p}= \pm a / 3<211\right]\right)$ Shockley partial dislocations. This drawing motion results in bounding partial dislocations that have the same Burgers vector but are oppositely signed, i.e. dislocation dipoles. In TEM the usual extinction rules allow for the determination of the fault plane and the direction of $b_{p}$, but it is much more difficult to identify the exact nature (intrinsic or extrinsic) of the stacking fault and the magnitude of $\mathbf{b}_{\mathrm{p}}$. The difficulties, which are related to the overlapping of the stacking fault and partial dislocation contrasts, are covered in detail in [11]. Because of these difficulties, comparisons with

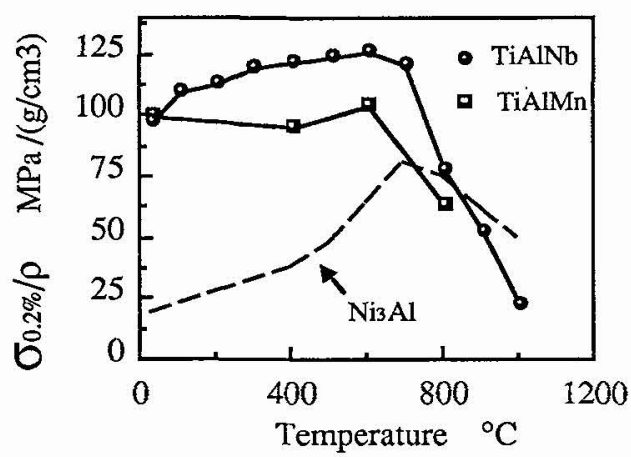

Fig. 1. - Temperature dependence of the yeld stress normalized by the density for two TiAl and $\mathrm{Ni} 3 \mathrm{Al}$ [13] polycrystalline alloys.

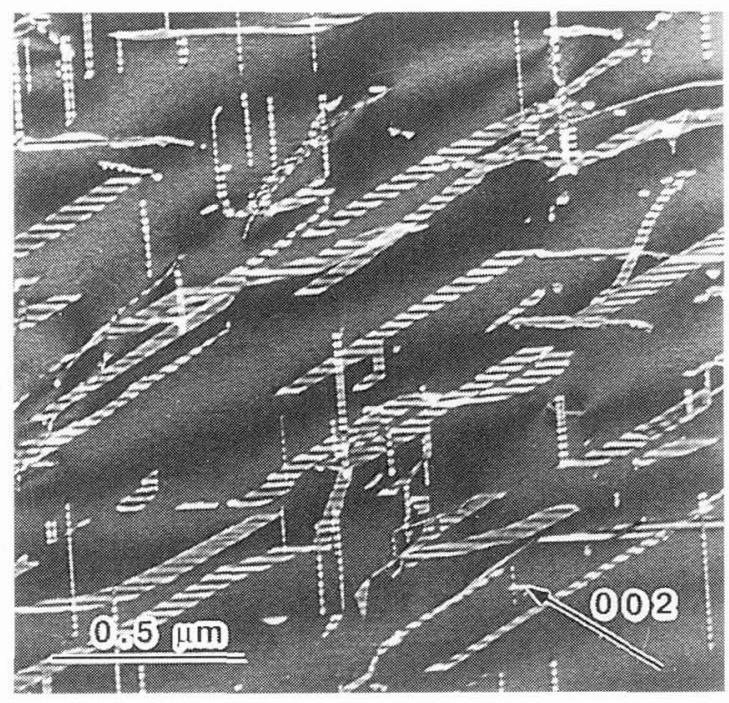

Fig. 2. -- Overview of the microstruture for $\mathrm{Ti}_{46} \mathrm{Al}_{52} \mathrm{Mn}_{2}$ deformed at RT; weak-beam (g,2.5g). 
computer simulated images have been used to characterize all of the stacking fault dipoles that were observed in this study.

The vast majority (approximately 95\%) of the stacking fault dipoles that were observed after RT deformation in both alloys were found to be of the type identified by Hug [2], i.e. extrinsic stacking faults bounded by single Shockley partial dislocations. An example of a stacking fault dipole in $\mathrm{Ti}_{46} \mathrm{Al}_{52} \mathrm{Mn}_{2}$ is shown in fig. 3(a). The extinction rules were used to determine both the fault plane and the direction of $b_{p}$ and $\pm \mathbf{g}$ experiments were used to determine the sign of $\mathbf{b}_{\mathrm{p}}$, but direct comparisons with simulations of the two remaining possible dipole configurations, see figs. 3(b) and 3(c), were used to determine the exact configuration of the defect. Figure 3 clearly shows that the observed stacking fault dipole is an extrinsic fault that is bounded by single Shockley partial dislocations.

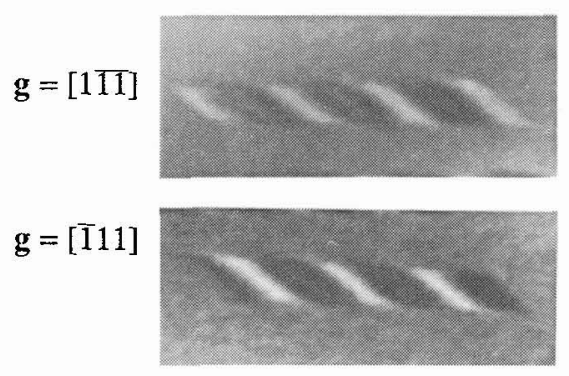

Experimental Observation

(a)
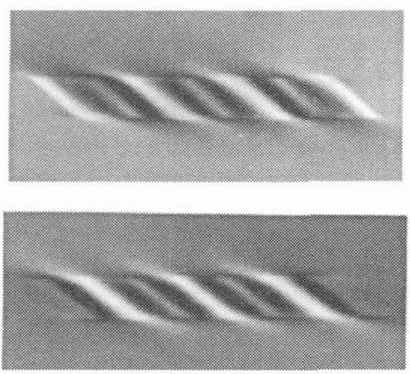

$\mathrm{ESF}-\mathrm{b}_{\mathrm{p}}=1 / 6[1 \overline{1}]$

(b)
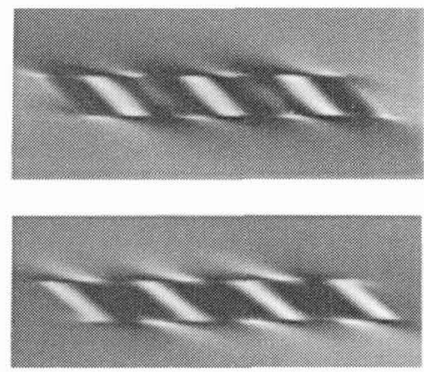

$\mathrm{ISF}-\mathrm{b}_{\mathrm{p}}=1 / 3[11 \overline{2}]$

(c)

Fig. 3. -- Faulted dipole in Ti46 $\mathrm{Al}_{52} \mathrm{Mn}_{2}$ after RT deformation. The bright field (BF) experimental images (a) are compared to the simulated images for the two possible configurations $(b, c)$. The dipole is an extrinsic fault bounded by a single Shockley partial dislocation.

By contrast, the remaining 5\% of the stacking fault dipoles formed during RT deformation were found to be of the type described by Zhang [3], i.e. extrinsic stacking faults bounded by double Shockley partial dislocations. Moreover, all of the stacking fault dipoles observed in the $\mathrm{Ti}_{46} \mathrm{Al}_{53} \mathrm{Nb}_{1}$ specimen that was deformed at $80 \mathrm{~K}$ have been found to be bounded by double Shockley partial dislocations. An example of this type of faulted dipole is given in fig. 4(a). As in the previous example, the final determination was done by direct comparison with simulations of the two configurations presented in figs. 4(b) and 4(c). In this case, the extrinsic fault was bounded by double Shockley partial dislocations.

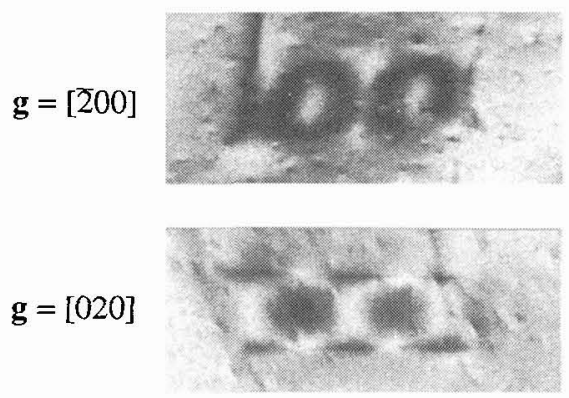

Experimental Observation.

(a)
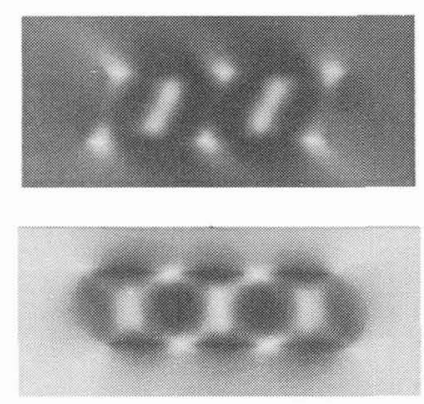

$\mathrm{ESF}-\mathbf{b}_{\mathrm{p}}=1 / 3[121]$

(b)
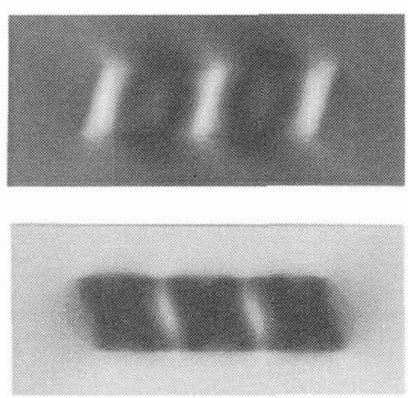

$\mathrm{ISF}-\mathbf{b}_{\mathrm{p}}=1 / 6[1 \overline{2} 1]$

(c)

Fig. 4. - Faulted dipole in $\mathrm{Ti}_{46} \mathrm{Al}_{53} \mathrm{Nb}_{1}$ after deformation at $80 \mathrm{~K}$. The $\mathrm{BF}$ experimental images (a) are compared to the simulated images for the two possible configurations $(b, c)$. The dipole is an extrinsic fault bounded by a double Shockley partial dislocation. 
Preliminary weak-beam observations indicate that the faults bounded by single Shockley partial dislocations are associated with the dissociation of $\mathrm{a} / 2<112]$ superdislocations according to the global reaction $a / 2[\overline{11} 2]->a / 3[\overline{112}]+$ SESF $+a / 6[\overline{112}]$, and that the faults bounded by double Shockley partial dislocations are related to the dissociation of a<101] superdislocations according to the reaction a[101] $\rightarrow$ $a / 3[112]+S E S F+a / 3[211]$. In this light, the observations of two different types of stacking fault dipoles may be explained by the activation of $a<101]$ superdislocations at low temperatures and of $a / 2<112$ ] superdislocations at temperatures near RT. This change in dislocation mechanism may be caused by the activation of different sets of dislocations, or by the dissociation of the $a<101]$ super dislocation by the reaction $a[\overline{101}]->a / 2[\overline{1} 10]+a / 2[\overline{11} 2]$ that has been proposed in [2]. At present, the reason for this change in dislocation mechanism is still unknown, but work in this area is continuing.

\section{Summary of results.}

1. TEM observations of stacking fault dipoles have been characterized by comparisons with computer simulated images.

2. The results of these comparisons confirmed the existence of extrinsic stacking faults that are bounded by either:

(i) single Shockley partials $\left.\left(b_{p}=a / 6<112\right]\right)$ as observed by Hug et al. [2], or

(ii) double Shockley partials $\left.\left(b_{\mathrm{p}}=\mathrm{a} / 3<211\right]\right)$ as proposed by $Z$ hang et al. [3].

3. The single Shockley partial dipoles were observed to dominate the microstructure of specimens deformed at RT, while the double Shockley partial dipoles were more prevalent at lower temperatures $(\sim 80 \mathrm{~K})$.

4. This change in the fault dipole geometry is believed to be related to a change in the type of the super dislocations that control deformation.

\section{References}

[1] Shechtman D., Blackburn M.J. and Lipsitt A, Met. Trans. 5 (1974) 1373.

[2] Hug G., Loiseau A. and Lasalmonie A., Phil. Mag. A 54 (1986) 47.

[3] Zhang Y.G., Xu Q., Chen C. Q. and Li H.X., Sripta Met. et Mat. 26 (1992) 865.

[4] Kim Y.W. and Dimiduk D., J.O.M. (august 1991) 40.

[5] Wardle S., Phan I. and Hug G., Phil. Mag. A 67 (1993) 497.

[6] Farenc S., Coujou A. and Couret A., Phil. Mag. A 67 (1993) 127.

[7] Farenc S., Ph.D. Thesis, University of Toulouse (1992).

[8] Court S.A., Vasudevan V.K. and Fraser H.L., Phil. Mag. A 61 (1990) 141.

[9] Hug G., Loiseau A. and Veyssiere P., Phil. Mag. A 57 (1988) 499.

[10] Greenberg B. A., Antonova O. V., Karkina L. E., Notkin A. B. and Ponomarev M. V., IV , Acta Metall. Mater. 40 (1992) 823.

[11] Viguier B., Hemker K.J. and Vandershaeve G., submited for publication in Phil. Mag. A.

[12] Schäublin R. and Stadelmann P, Mat Science and Eng., in press.

[13] Thornton P.H., Davies R.G. and Johnson T.L., Met. Trans. 1 (1970) 207. 